\title{
The effect of organisational culture on organisational performance: the mediating role of intrapreneurship
}

Research Article

Mehmet Kiziloglu*

Department of Management and Organization, Pamukkale University, Turkey

\begin{abstract}
The aim of this research is to examine the effect of organisational culture on organisational performance in the context of the hospitality industry in the UK. Organisational culture was studied based on the Denison model. The study was conducted based on a quantitative research method and primary data was collected, with questionnaires, from 440 employees in the hospitality industry. The study reveals that organisational culture significantly affects organisational performance. Moreover, it is found that adaptability and mission are two key elements of organisational culture that significantly affect organisational performance. Furthermore, intrapreneurship fully mediates the relationship between adaptability and organisational performance. In addition, intrapreneurship fully mediates the relationship between mission and organisational performance. Hence, managers working in the hospitality industry are required to give considerable attention to adaptability and mission as two important elements of organisational culture in order to achieve intrapreneurship, and to ultimately improve the performance of an organisation.
\end{abstract}

Keywords: Organisational culture; adaptability; mission; consistency; involvement; intrapreneurship; organisational performance

(C) Sciendo

\section{INTRODUCTION}

Business managers and organisations face several challenges in the competitive global marketplace, including dealing with an increase in global price competition and ensuring a high satisfaction level among stakeholders (Ibarra-Cisneros et al., 2020). In this context, managers face various challenges in the establishment of an effective organisational culture, which is considered an important aspect of improving performance and productivity (Kaouache et al., 2020). The long-term existence and success of a business depends on its improved performance and profitability. Business expansion is dependent on the ability of the organisation to improve performance, so there is a need to focus on aspects that can help to enhance the performance of an organisation (Bendak et al., 2020). The lack of an effective organisational culture is considered the main cause of an organisation's poor performance (Wziątek-Staśko et al., 2020). Therefore, it is important for business managers to understand the importance of organisational culture for the purpose of improving their organisation's productivity and performance (Reino et al., 2020). In the hospitality industry, it is the responsibility of management to focus on those aspects that can help in improving performance, in order to succeed in today's competitive business world. Based on the findings of Kaouache et al. (2020), the management team of organisations need to devote particular attention to the culture of their respective firms when they are designing and implementing key business strategies. This present research focuses on analysing the importance of organisational culture in terms of improving organisational performance, especially in the context of the hospitality industry.

Organisational culture is linked with the behaviour of the people working within an organisation. Companies exist in a particular culture, which affects the way their employees perceive, feel, and behave (Wziątek-Staśko et al., 2020). Organisational culture is known as a powerful force that affects the work life of employees. Hence, employees 
and managers do not work in a value-free environment: they are organised, directed, and tempered through the culture of an organisation (Lockhart et al., 2020). Therefore, the management of an organisation is required gain a complete understanding of the importance of organisational culture in terms of improving performance. This research study provides an understanding of the relationship between organisational culture and an organisation's performance in the hospitality industry. In the existing literature, a few studies have investigated the importance of organisational culture in terms of enhancing performance (Tortorella et al., 2020; Zucchella et al., 2019). However, none of these studies focused on examining organisational culture through the Denison model or the influence of each element of organisational culture as identified through the Denison model on the performance of the organisation in the context of the hospitality industry (Chilla et al., 2014).

Another key aspect of this study is the investigation of the mediating effect of intrapreneurship on the relationship between organisational culture and performance. As a result of rapid change in market conditions, as well as uncertainty in environmental conditions, organisations are being forced to focus on offering innovative products and services (Gürkan and Çiftci, 2020). Innovation in products and services gives additional value to an organisation, as well as the whole economy, and also helps to support the growth of the sector (Scuotto et al., 2017). While many researchers and practitioners have focused on entrepreneurship, none of them have focused on investigating the role of intrapreneurship in enhancing an organisation's performance, especially within the framework of organisational culture (Tortorella et al., 2020). It is important to examine entrepreneurship and innovation at the organisational level and to analyse how organisational culture is linked with intrapreneurship and, in turn, the performance of an organisation. Therefore, this research study focuses on investigating the mediating effect of intrapreneurship on the relationship between organisational culture and performance.

In the literature, many researchers have tried, without success, to explain the impact of different organisational practices on organisational performance. There are various human resource strategies that have been considered as important predictors of organisational performance. The relationship between any of the human resource strategies and organisational performance is still considered a black box (Úbeda-García et al., 2018; Van Rhee and Dul., 2018). The present research attempts to unlock the black box by explaining the role of intrapreneurship in this complex relationship. Therefore, it contributes to the existing literature by analysing the ways in which human resource can enhance organisational performance. As organisational culture reflects human resource strategies (Miller, Ngunjiri and LoRusso, 2017), instead of considering one human resource strategy, this research attempts to contribute on a wider scale by considering organisational culture as a predictor of organisational performance.

When the culture of an organisation is not developed properly and effectively, this ultimately results in reducing the shareholders' return, as well as the profitability of the firm. Vnoučková and Urbancová (2020) found that around $72 \%$ of leaders in an organisation acknowledge the significance of organisational culture and intrapreneurship, but there are still $28 \%$ leaders who fail to recognise their importance in terms of enhancing organisational performance. The general business issue is that in some organisations, managers fail to carefully consider establishing an effective culture, with the result that performance and productivity are negatively impacted (Lockhart et al., 2020). Managers in the hospitality industry are often unable to design appropriate strategies related to the development of an effective organisational culture, which ultimately results in the failure of their organisations. The Denison organisational culture model, which is valid for research at all organisational levels, is a behavior-based model that can meet the application-oriented requests of managers by developing a quantitative approach that is directly linked to practice and is reliable (Denison and Mishra, 1995; Denison and Nieminen, 2014). In this context, culture can have an impact on many organisational variables, as well as on the organisational power used in organisations. Hence, this research study provides key guidance and information for hotels managers regarding ways of improving the performance of their organisation, through focusing on designing an effective organisational culture and giving importance to intrapreneurship.

\section{THEORETICAL BACKGROUND}

\section{Organisational culture}

A number of scholars have defined organisational culture. Romani et al. (2018) argue that organisational culture is a system of shared norms and values that have a significant impact on the behaviour of employees in an organisation. 
It includes shared assumptions, which have been developed and accepted by a specific group, in order to solve internal and external problems. According to Cooke and Rousseau (1998), organisational culture is defined as the shared beliefs and values from which members are required to work in a given unit. Every type of organisation has a unique culture involving shared norms and values (Lee et al., 2019). The presence of shared values in an organisational culture is something that significantly influences the behaviour of people in an organisation. Denison (1990) also expresses the culture of an organisation as the deep-rooted values, beliefs and assumptions accepted by its members.

Organisational culture includes integrated perceptions of work practices that are present within units in a company. According to Hofstede et al. (2005), organisational culture is a system of shared work practices that are affected through rituals and symbols, and which also include meanings that can be interpreted by members of the firm. As per this analysis, it is found that there is no consensus regarding the definition of organisational culture. However, it is generally agreed that organisational culture consists of key aspects such as values, practices, beliefs and assumptions, that are commonly accepted and which are used for guiding actions within an organisation (Ahammad et al., 2016). Organisational culture is considered as an important factor influencing the success of organisations. While operating in today's competitive business world, it is extremely important for the management of organisations to give considerable importance to the development of an effective organisational culture. This helps to enhance the performance of employees, which ultimately results in increasing the general organisational performance (Richter et al., 2016).

\section{Organisational performance}

Organisational performance is defined as a state of competitiveness of an organisation that is reached through a level of productivity and efficiency which helps that organisation to ensure a sustainable presence in the market (Lee et al., 2019). Organisational performance in Lee et al (2019) was studied through analysis of key elements of a balanced scorecard that outlines the essential elements ensuring the long-term success and competitiveness of an organization. It includes key elements such as financial outcomes, global market share, quality of products, and image in market (Ana-Maria et al., 2010). Organisational performance includes the analysis of the firm's performance against the identified objectives, and includes real outputs in comparison to intended outputs. Managers focus on three key outcomes when analysing performance, and these include shareholder value, financial performance, and market performance. Long-term success and competitive advantage depend on improved organisational performance. It is always important for organisations to focus on these factors and other elements that can help to enhance performance (Chilla et al., 2014).

\section{Theoretical framework and hypotheses}

The focus of the current research study is the use of Denison's model for understanding organisational culture and its relationship with intrapreneurship and organisational performance. This model has been used in the current research study because it can be applied for the purpose of evaluating the management approach and can be used for measuring the competitiveness of a business. The hospitality sector is generally managed through international chain management, so it is better equipped and has the ability to adapt to a changing business environment (Rahimi, 2017). Moreover, this model can be used for aligning internal factors indicated through its ability to enhance employee empowerment, entrench the key values of organisational culture, and develop teamwork. It is important for managers working within the hospitality industry to focus on taking account of the increased capability of organisational learning, integration, and coordination (Shahriari and Allameh, 2020).

The key focus of this model is the point that companies' performance can be enhanced through organisational culture. Companies apply this model in order to effectively manage change and to better recognise elements of organisational culture in which change is required. Moreover, this model can be applied to all levels of hierarchy. This model (shown in Figure 1) proposes two main dimensions representing the key characteristics of organizational culture, and twelve indicator levels representing the extent of inflexibility. This model has a direct impact on organisational culture and offers an innovative framework over other models of organisational culture (Quelhas et al., 2019). 


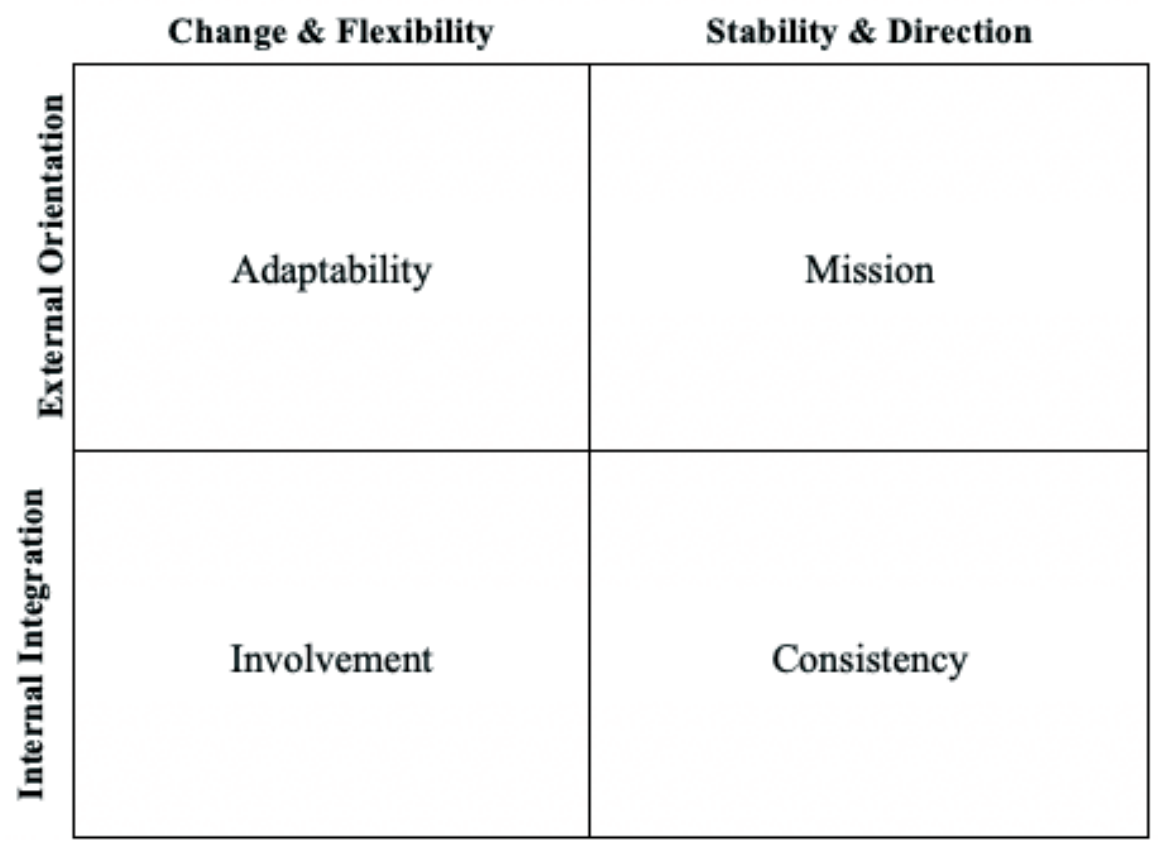

Figure 1: Theoretical model of organisational culture traits (Denison \& Mishra, 1995)

Certain specific traits are highlighted in the Denison Model of Organisational Culture, and it is important for a firm master these for the purpose of working effectively. The illustration shows that the centre of the model includes 'Beliefs and Assumptions'. These include deeply held elements of the identity of an organisation, which are generally difficult to access (Roscoe et al., 2019). There are three indexes of each trait. For example, 'Adaptability' includes 'Creating Change', 'Organisational Learning', and 'Customer Focus'. Based on Denison's research, it has been found that in order to ensure high effectiveness, it is important to achieve high cultural scores in all traits. Hence, effective companies are those that have an adaptive, consistent culture and one that fosters high involvement. Moreover, effective organisations should focus on building a shared sense of mission (Erthal and Marques, 2018).

Literature on organisational culture includes information on how effective organisational culture can be used by business managers for the purpose of improving performance and productivity (Halim et al., 2019). Most business managers believe that effective organisational culture is one of the biggest assets. However, when there is ineffective culture in an organisation, then it endangers the success of that organisation. Organisational culture is used by business managers to control and moderate the working environment of the whole organisation. In order to ensure the success of an organisation, it is important to have an effective and positive organisational culture. When there is strong culture in an organisation, this positively influences the behaviour of members of the firm, who start to behave in line with its values (Lee et al., 2019). Chen et al. (2019) argues a positive organisational culture helps to motivate employees to share their goals and values of the firm, which ultimately results in enhancing the performance of the firm. It is possible for business managers to establish an effective culture within the firm, for the purpose of improving performance and productivity. Effective organisational culture can promite excellent customer service, which also helps to create an innovative business environment.

The focus of the current research study is on four key elements of organisational culture, as identified through Denison (1990), namely, involvement, consistency, adaptability, and mission. These four elements are extremely important for developing and maintaining an effective organisational culture within the firm. Denison suggests that involvement and consistency are internal factors used to develop an effective organisational culture, while mission and adaptability are external factors. The section below includes a detailed analysis and discussion of key elements of organisational culture as identified in the Denison Model of Organisational Culture.

Involvement: this is one of the key elements of organisational culture that can affect the effectiveness of the culture of the firm. When there is high involvement within the organisation, transparent communication takes 
place within that organisation (Carraher et al., 2016). Furthermore, Ooi et al. (2020) find that high involvement in organisational culture includes employee-focused leadership and strong interpersonal relationships. When employees participate in the decision-making process of an organisation, they also start to show increased responsibility and accountability for their actions. In the same way, when organisational culture has a high level of involvement, there is a positive relationship between the high level of employee participation in decision-making and improved performance. However, Dirisu et al. (2018) argue that a high level of employee involvement within an organisation results in a decrease in specialisation, due to the increased difficulty in identifying the responsible person to perform a particular task.

However, Halim et al. (2019) claim that a high level of employee involvement in the process of decision-making can make a significant contribution to enhancing the effectiveness of organisational culture. Along with this, it is also argued that extent of organisational culture effectiveness depends on geographical location of the firm, too. Mason et al. (2020) examined the relationship between organisational culture and business performance in terms of geographical location. They found that a high degree of involvement resulted in enhancing the effectiveness of organisational culture and improved performance in the context of firms operating in Thailand. Based on an analysis of the literature, it is clear that no study has focused on investigating the impact of involvement as a key element of organisational culture on organisational performance in the context of the hospitality industry. The following hypothesis has therefore been developed:

\section{H1 a: Involvement has a significant impact on organisational performance.}

Consistency: another important element of organisational culture is consistency. Previous research findings claim that consistency in a company reflects the effectiveness of organisational culture. Chen et al. (2019) argue that this is one of the basic factors that can be used for creating a strong organisational culture and improving the performance of employees. However, Cui et al. (2018) claim that a high level of consistency is not always directly linked with the commitment and performance of employees. When an organisation has a high level of stability, then it helps them to remain focused and predictable with the passage of time. An organisation is required to be stable because it is specifically linked with a high return on assets, growth of sales, and growth of assets.

Consistency is defined as the integration of all business activities and proper monitoring, while setting up an internal system of governance. Ibarra-Cisneros et al. (2020) find that there are strong roots of consistency in internal focus. As a result of high consistency, employees get an understanding of how their work and performance influence the work of others and vice versa. This helps employees to focus on ensuring the smooth coordination of work, for the purpose of better serving the firm. It is important for the management of an organisation to ensure proper coordination and integration, so that all employees can get a complete understanding about how their work impacts the work of others. This approach can improve the overall performance of an organisation, because each individual makes sure that he or she performs well, as efficiency and the effectiveness of others depend on that individual performance. Based on this analysis, the following hypothesis has been developed:

\section{H1 b: Consistency has a significant impact on organisational performance.}

Adaptability: is defined as the capability of business managers to perceive and respond to external business environments. An effective organisational culture makes managers highly passionate and responsive to external and internal factors (Low et al., 2020). In the context of adaptability, business managers have the capability to modify the existing organisational culture for the purpose of accommodating necessary changes. The main change consists of achieving improvement in internal aspects, such as the modernisation of internal departments and products, in order to give a proper response to external competition. Generally, business managers become involved in modifying and adopting new situations in a company, by means of different internal and external factors. Lockhart et al. (2020) claim that employees show a strong competency in adapting, restructuring and reinstituting internal processes, attitudes and behaviours, in response to certain external factors. This is one of the critical elements of organisational culture that can be used to promote the performance of business, especially when an organisation has the capacity to change in response to the environment while focusing on employees and customers. When an organisation has a high level of flexibility, it is specifically related to a higher level of innovation, creativity and rapid response to varying demands of employees and customers. Based on a review of the literature, the following hypothesis has been developed: 
H1 c: Adaptability has a significant impact on organisational performance.

Mission: the mission of an organisation is an important element of organisational culture and is defined by business managers through identifying specific aims and meanings to every key part of firm's mission. The organisational mission of a firm includes clear direction and vision, strategic decisions and intentions, and key objectives of the firm (Carvalho et al., 2019). When business managers consider developing an effective organisational culture, they focus on using the mission and vision of their organisation in order to determine the short- and long-term goals (Sozuer et al., 2017). However, Vnoučková and Urbancová (2020) argue that organisational mission is used by business managers for the purpose of providing clear direction to internal and external stakeholders. Business managers in an organisation are responsible for aligning the organisational culture with the mission of that organisation. Business managers believe that it is important to make a successful alignment between the culture of an organisation and its mission, and that it is the responsibility of business managers to focus on securing the success of the company. As per the findings of most of the existing studies, the alignment of mission with all activities and tasks performed within an organisation is extremely important, in order to ensure an improved business performance. However, the influence of organisational mission on organisational performance has not been examined in the literature. Hence, the following hypothesis has been developed:

H1 d: Mission has a significant impact on organisational performance.

\section{Organisational culture in the hospitality industry}

The hospitality industry is a service sector for which competitiveness depends on the development of the appropriate organisational culture. In order to ensure the success of the business, there is a need to focus on value development, to raise work satisfaction. This also results in enhancing a positive attitude and positive behaviour among employees (Chahal and Poonam, 2017). The organisational culture within the hospitality industry refers to a soft system tool, which has a significant effect on decision-making in an organisation, the development of leadership, the development of a human resource programme, and other policies. When companies get the appropriate cultural support, they benefit from a positive attitude among employees, ethical behaviour and career satisfaction. With the help of these positive advantages, the performance and competitiveness of an organisation are strengthened (Segovia-Pérez et al., 2019). In the hospitality industry, employees play a significant role. The service performance of staff is used to determine the interaction in offering services to hotel guests from different countries. The management of an organisation has the responsibility to develop a strong culture through vision congruence, teamwork, innovation, a strong level of coordination among members, and the development of employees. These aspects are considered as extremely important in the delivery of high -quality service (Arjona-Fuentes et al., 2019).

\section{Intrapreneurship in service sectors and hospitality}

Intrapreneurship is a concept whereby people within an organisation are defined as having entrepreneurial characteristics. In the hospitality industry, innovation is considered an important element for hotels for the purpose of remaining part of the game (Chen et al., 2019). In order to successfully struggle with innovation, intrapreneurship is known as an important enabler for enhancing performance and for adopting innovation (Manning, 2018). In the hospitality industry, entrepreneurs can be differentiated through their innovative ideas that can be used for bringing positive change in the business. In the service sector, intrapreneurship is known as an important element that can help in improving performance. As the hospitality industry is a high-tech service industry, it is extremely important to consider intrapreneurship, in order to remain competitive (Odor, 2018).

\section{Mediating role of intrapreneurship}

Intrapreneurship is referred to as entrepreneurship in a company, with a particular focus on innovation. The term 'intrapreneurship' has gained in popularity over the last three decades. It involves, among other things, marketing new goods or services (Mees et al., 2016). Ooi et al. (2020) claim that intrapreneurship is a sub-field of entrepreneurship, which includes innovative activities within the firm, and helps in the creation of new products or services. This ultimately helps to strengthen the competitive position of the company. However, it has been argued by Mason et al. (2020) that intrapreneurship usually focuses on the non-core activities of business.

While the focus on intrapreneurship within an organisation is important for gaining competitive advantage, there is also a need to focus on maintaining an effective organisational culture. Business managers are required to 
carefully consider key elements of organisational culture, such as involvement and adaptability. It is always important to have an aspect of involvement in an organisation, in order to ensure a high level of intrapreneurship. When all employees in an organisation are properly engaged within the firm, they can start to focus on sharing their key ideas and perspectives with each other and with their managers. This ultimately helps the firm to achieve innovation and to focus on entrepreneurship (Halim et al., 2019). It has been found by Cui et al. (2018) that a high level of flexibility in an organisation is important in order to ensure high level of entrepreneurship within the firm. The innovation offered by the firm depends very much on its ability to adapt to certain internal and external changes. A high level of adaptability is important, in order to achieve intrapreneurship, because flexibility and adaptability allow the firm to achieve innovation. In today's competitive business world, entrepreneurship is extremely important for gaining long-term success (Kyriacou and Panigyrakis, 2020). Another important element of organisational culture that can influence intrapreneurship is consistency within the organisation. Consistency within an organisation is extremely important, in order for it to focus on entrepreneurship. There is a need to ensure a smooth integration between business activities and the internal system of governance. With the help of proper monitoring and integration, the firm can achieve entrepreneurship, which is ultimately important for ensuring long-term success (Chen et al., 2019). In order to focus on intrapreneurship, it is also important for the firm to have an appropriate mission. An organisation should have a defined mission in order to make entrepreneurs focused towards that specific mission and objectives. This approach can ultimately help to achieve innovation and to sustain competitive advantage. Based on this analysis, the following hypotheses have been developed:

H2 (a) Intrapreneurship mediates the relationship between involvement and organisational performance.

H2 (b) Intrapreneurship mediates the relationship between consistency and organisational performance.

H2 (c) Intrapreneurship mediates the relationship between adaptation and organisational performance.

H2 (d) Intrapreneurship mediates the relationship between mission and organisational performance.

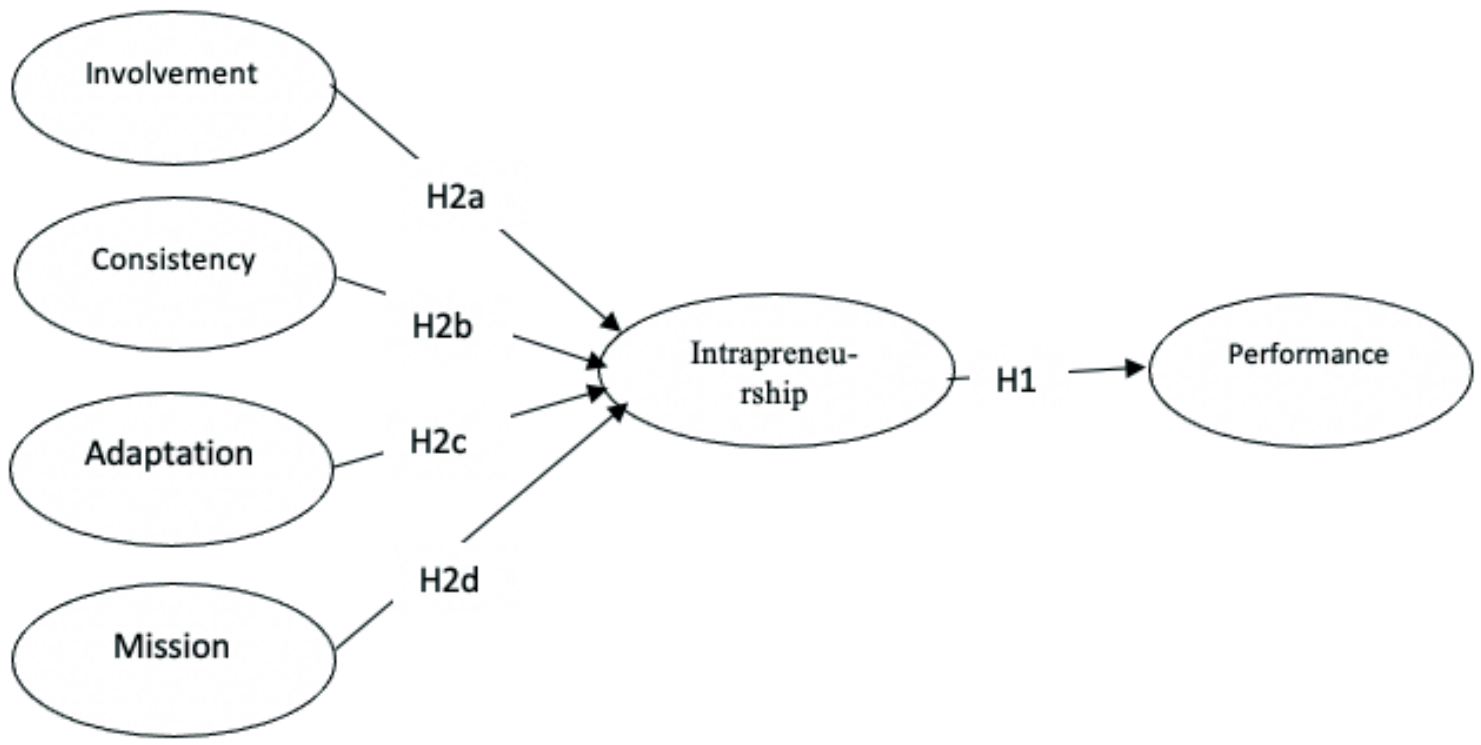

Figure 2: Theoretical framework 


\section{METHODS}

\section{Sample and methods}

This research study is based on a quantitative research method, according to which primary data was collected from 440 employees working in the UK hospitality industry. We incorporated large, small, and medium-sized business, in order to increase the generalisability of the findings. We only considered the hospitality industry, to ensure the sample homogeneity. For data collection, we were given access to the official database of hospitality industry employees. We obtained the email addresses and telephone numbers of all employees working in the industry and randomly selected 1,250 and invited them to complete the questionnaire. However, this research could only obtain 440 useable and complete questionnaires, making a response rate of 35\%. Of these 440 employees, the majority were aged 26-35 years, male, graduates of high school or equivalent schools and those who are still students at the university.

Table 1. Demographics

\begin{tabular}{|c|c|c|c|}
\hline & & $\mathbf{n}$ & $\%$ \\
\hline \multirow[t]{5}{*}{ Age } & below 25 years & 30 & 6.8 \\
\hline & $26-35$ years & 210 & 47.8 \\
\hline & $36-45$ years & 180 & 40.9 \\
\hline & $46-55$ years & 15 & 3.4 \\
\hline & above & 5 & 1.1 \\
\hline \multirow[t]{2}{*}{ Gender } & Male & 240 & 54.5 \\
\hline & Female & 200 & 45.5 \\
\hline \multirow[t]{2}{*}{ Education } & Undergraduate & 290 & 65.9 \\
\hline & Graduate & 150 & 34.1 \\
\hline
\end{tabular}

For estimating the confirmatory factor analysis, the maximum likelihood estimation was applied, where IBM AMOS 23.0 software was used. The same software was used for estimating the direct and indirect effects.

\section{Variables and Measurement}

All variables were measured on the basis of a five-point Likert scale and different items were identified for each variable. We used literature-based measures for all variables. We adapted scales for 1) intrapreneurship, 2) organisational culture, and 3) organisational performance from 1) Heinonen and Korvela (2003), 2) Denison et al. (2014), and 3) Ana-Maria et al. (2010). Organisational culture has the dimensions of involvement, consistency, mission, and adaptability. Intrapreneurship has the dimensions of encouragement by management and organisation, individual motivation, transparency, openness and communality, individual competence, enabling working environment, encouragement to make innovations, and development. Organisational performance has the dimensions of financial results, high global market share, high-quality products, and good image. Managerial position (i.e., lower, middle, and senior) is taken as a control variable in this study, due to its potential impact on intrapreneurship. 
Table 2. Summary of CFA fit indices for all constructs

\begin{tabular}{ccccccccccc}
\hline & CR & AVE & CA & CFI & GFI & RMSEA & RMR & $\chi^{2}$ & df \\
\hline \hline Involvement & 0.874 & 0.636 & 0.884 & 0.988 & 0.992 & 0.079 & 0.030 & $7.545^{\star}$ & 2 \\
Consistency & 0.859 & 0.670 & 0.836 & 1.00 & 1.00 & 0.511 & 0.000 & $346.23^{\star}$ & 3 \\
Adaptation & 0.822 & 0.608 & 0.836 & 1.00 & 1.00 & 0.464 & 0.00 & $286.005^{\star}$ & 3 \\
Mission & 0.920 & 0.743 & 0.848 & 0.972 & 0.977 & 0.147 & 0.037 & $21.087^{\star}$ & 2 \\
Intrapreneurship & 0.841 & 0.718 & 0.947 & 0.892 & 0.885 & 0.171 & 0.067 & $192.833^{\star}$ & 14 \\
$\begin{array}{c}\text { Organizational } \\
\text { performance }\end{array}$ & 0.830 & 0.696 & 0.801 & 0.920 & 0.940 & 0.244 & 0.060 & $54.078^{\star}$ & 2 \\
\hline
\end{tabular}

CF - Composite Reliability; CA - Cronbach's Alpha; AVE - Average Variance Extracted, CFI - Comparative Fit Index; GFI - Goodness Fit Index; RMSEA - Root Mean Squared Error of Approximation; RMR - Root Mean Squared Residual; $\chi 2$ - Chi Squared Test; df - Degree Freedom

A confirmatory factor analysis with a maximum likelihood method was applied and the items with factor loadings of less than 0.60 were deleted. Researchers such as Albright and Park (2009) suggest that reliability and convergent validity can be assessed through Composite Reliability (CR), Average Variance Extracted (AVE) and Cronbach's Alpha (CA). After deleting the problematic items, we found that all values were within an acceptable range (see Table 2). The acceptable values for $C A$ and $C R$ are above 0.70 and 0.50 for AVE. From this, it appears that the measures adopted in this research are valid and reliable. The values of CFI, GFI, RMR, RMSEA \& X2 are also within the acceptable range (Mair et al., 2016), showing a good fit for the models.

Table 3. Mean, standard deviation and inter-correlation

\begin{tabular}{|c|c|c|c|c|c|c|c|c|}
\hline & Mean & S.D. & 1 & 2 & 3 & 4 & 5 & 6 \\
\hline Involvement & 3.67 & 0.880 & 0.79 & & & & & \\
\hline Consistency & 3.65 & 0.876 & $.523^{\star \star}$ & $0 . .81$ & & & & \\
\hline Adaptability & 3.76 & 0.792 & $.405^{\star \star}$ & $.546^{* *}$ & 0.77 & & & \\
\hline Mission & 3.70 & 0.853 & $.387^{\star *}$ & $.424^{* *}$ & $.658^{* *}$ & 0.86 & & \\
\hline Intrapreneurship & 3.75 & 0.837 & $.258^{* *}$ & $.540^{* *}$ & $.681^{* *}$ & $.569^{* *}$ & 0.97 & \\
\hline Performance & 3.75 & 0.838 & $.400^{\star *}$ & $.504^{* *}$ & $.672^{* *}$ & $.669^{* \star}$ & $.803^{* *}$ & 0.83 \\
\hline
\end{tabular}

**. Correlation is significant at the 0.01 level (2-tailed).

Note: Bold figures are square root of AVE.

To find discriminant validity, a comparison of square root of AVE was made with inter-correlations of all variables. Table 3 illustrates that there is no issue of discriminant validity among the variables, as the square root of AVE is greater than the correlation of all the variables. When data is found from a single source at the same time for all variables, there is a higher chance of a common method variance (MacKenzie and Podsakoff, 2012). However, procedural measures, as suggested by Podsakoff et al. (2013), were also used to reduce this error. For example, while we retained the anonymity and confidentiality of information, CMV could still be a serious problem for any study. Herman's single-factor test has shown that a single factor has a value of 40.902, which means that there is no issue of common method bias.

\section{FINDINGS AND RESULTS}

In this research, mediation analysis was performed using a bootstrapping procedure, where $90 \%$ bias corrected confidence intervals were used and the bootstrapping sample was 1250 (see Figure 1). To perform this analysis, we used a structural equal model (SEM), where organisational culture was an exogenous variable, intrapreneurship was a mediator, and organisational performance was an endogenous variable. 
Table 4. Path Analysis - Direct Impact of organizational culture on organizational performance

\begin{tabular}{|c|c|c|c|c|c|}
\hline & & SE & Lower bounds & Upper bounds & Significance Value \\
\hline & Managerial Position $\rightarrow$ OP & -.005 & -.039 & .209 & .831 \\
\hline & Intrapreneurship $\rightarrow$ OP & $.603^{*}$ & .060 & .685 & .001 \\
\hline $\mathrm{H} 1$ (a) & Involvement $\rightarrow \mathrm{OP}$ & -0.134 & .099 & .193 & .217 \\
\hline $\mathrm{H} 1$ (b) & Consistency $\rightarrow \mathrm{OP}$ & -.032 & -.021 & .034 & .441 \\
\hline $\mathrm{H} 1(\mathrm{c})$ & Adaptation $\rightarrow \mathrm{OP}$ & $.064^{*}$ & .173 & .151 & .004 \\
\hline $\mathrm{H} 1$ (d) & Mission $\rightarrow$ OP & $.240^{\star}$ &.- .039 & .308 & .001 \\
\hline
\end{tabular}

The managerial position was used as a control variable in this study, and it was found that it is not related to organisational performance. Therefore, it was not used for further testing. Control variables are added to analyse if they do have any impact on the model, so their existence is controlled. As it was found that managerial position does not have a significant impact on organisational performance, this can be ignored. For testing the hypotheses, we estimated the direct effects of organisational culture and intrapreneurship on organisational performance. The analysis, as shown in Table 4, shows that adaptation $(\beta=0.064, p=0.004)$ and mission $(\beta=0.240, p=0.001)$ have a significant impact on organisational performance, so hypotheses $\mathrm{H} 1 \mathrm{C}$ and $\mathrm{H} 1 \mathrm{~d}$ were accepted. Any hypothesis is considered to have the adequate support of data when $\mathrm{p}<0.05$ and $\mathrm{H} 1 \mathrm{C}$ and $\mathrm{H} 1 \mathrm{~d}$ matched this criterion. As the pre-conditioning of Baron and Kenny (1986) were not fulfilled, and $\mathrm{H} 1 \mathrm{a}$ and $\mathrm{H} 1 \mathrm{~b}$ were not accepted, these two predictors were not considered for the analysis of mediation.

Table 5. Path analysis - Indirect impact of organizational culture on organizational performance

\begin{tabular}{llcccc}
\hline & & Effect & Lower bound & Upper bound & Significance Value \\
\hline \hline $\mathrm{H} 2(\mathrm{a})$ & Involvement $\rightarrow$ Intrapreneurship $\rightarrow$ OP & $-.049^{\star}$ & -.152 & -.049 & .001 \\
$\mathrm{H} 2(\mathrm{~b})$ & Consistency $\rightarrow$ Intrapreneurship $\rightarrow$ OP & $.228^{\star}$ & .125 & .0228 & .001 \\
$\mathrm{H} 2(\mathrm{c})$ & Adaptation $\rightarrow$ Intrapreneurship $\rightarrow$ OP & $.345^{\star}$ & .204 & .345 & .001 \\
$\mathrm{H} 2(\mathrm{~d})$ & Mission $\rightarrow$ Intrapreneurship $\rightarrow$ OP & $.176^{*}$ & .091 & .176 & .001 \\
\hline
\end{tabular}

With reference to Table 5, the analysis of the indirect path analysis shows that the indirect effect of adaptation on organisational performance through intrapreneurship is significant $(\beta=0.345, p=0.001)(90 \% \mathrm{Cl}: 0.204,0.345)$, hence full mediation exists, and $\mathrm{H} 2 \mathrm{c}$ is supported. Likewise, the indirect effect of mission on organisational performance through intrapreneurship is significant $(\beta=0.176, p=0.001)(90 \% \mathrm{Cl}: 0.091,0.176)$, hence full mediation exists and $\mathrm{H} 2 \mathrm{~d}$ is supported. Full mediation exists when the relationship between independent and dependent variable becomes void without the existence of a mediator. Partial mediation is where the relationship between independent and dependent variable still exists, if the mediator is removed. Consequently, it was found that the relationship between mission and adaptation will not exist, if the mediator is removed, which is a meaningful finding of this study, presenting an indirect relationship. 


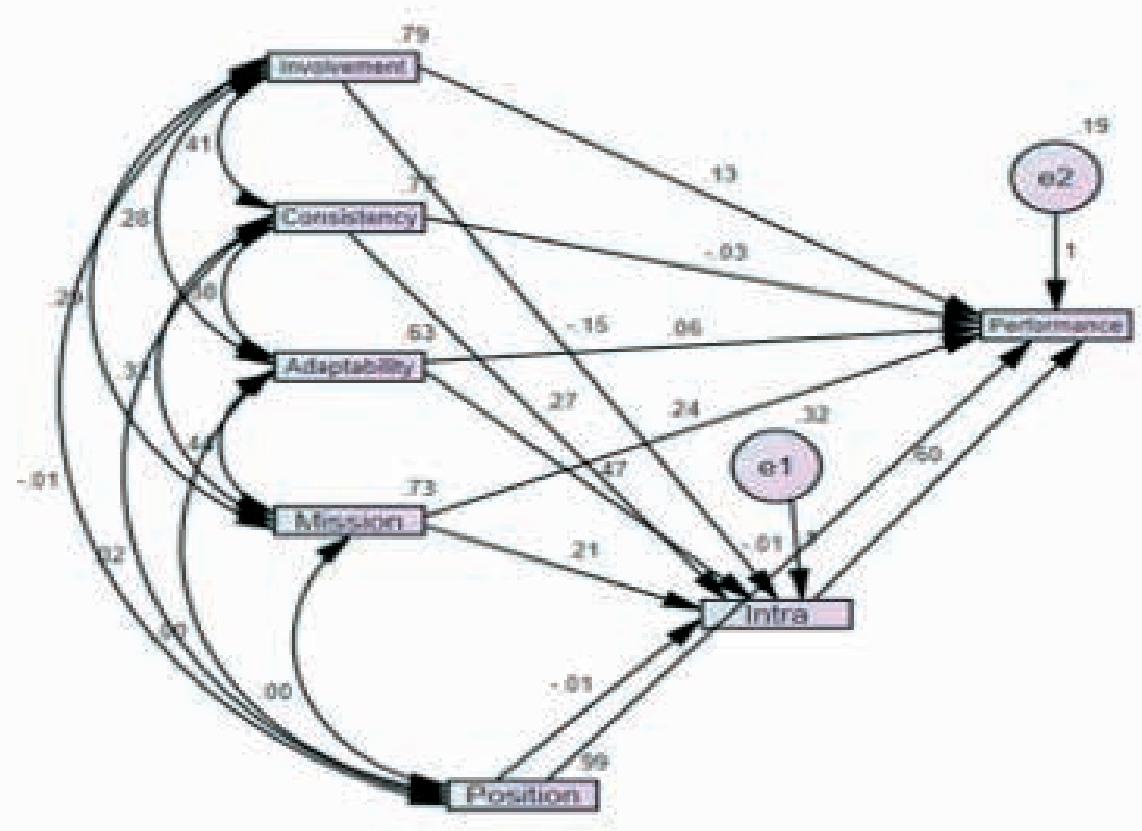

Figure 3. Indirect and direct path analysis

In this research, SEM analysis was performed. Figure 1 demonstrates the direct and indirect path analysis results; and the coefficients are represented at the path of each relationship.

\section{DISCUSSION}

This research study has found a significant impact of organisational culture on organisational performance. Adaptation and mission are two important elements of organisational culture that significant impact organisational performance. This is consistent with the findings of Mees et al. (2016), who claim that adaptation is an important element of organisational culture and needs to be present in an organisation in order to ensure high performance. Roscoe et al. (2019) also state that it is extremely important for an organisation to focus on adapting to internal and external changes, in order to gain long-term success. Similarly, Sinha and Dhall (2020) found that an organisation should be able to adapt to external factors and changes, in order to satisfy its stakeholders. This ultimately helps to enhance performance. Furthermore, the study has supported the hypothesis that mission has a significant impact on organisational performance. This is similar to the findings of Tortorella et al. (2020), who state that the improved performance of an organisation depends on its identified mission. When the business managers become involved in properly identifying the mission and key objectives of the firm, the employees can focus on following the approaches and strategies that help to fulfill their specific objectives and goals.

However, as per the findings of this research study, $\mathrm{H} 1 \mathrm{a}$ and $\mathrm{H} 1 \mathrm{~b}$ were not supported, which means that the study did not support the direct impact of involvement and consistency as elements of organisational culture on organisational performance. Therefore, involvement does not significantly affect the performance of an organisation. This finding is opposite to the research conducted by Vnoučková and Urbancová (2020), who find that involvement is an important element of organisational culture, which significantly affects the performance of an organisation. Besides this, Chen et al. (2019) state that when employees in an organisation become involved in key activities and decision making, they feel motivated and committed, as well as showing improved performance. However, in contrast with this, the findings of the current study are consistent with those of Sebastião et al. (2017), who claim that it is not always important to have improved organisational performance due to high involvement. There is a possibility that even while employees may be involved in decision-making, they are not always provided with external rewards and perks. As a result, their motivation level is low and their performance is correspondingly 
reduced. According to Mason et al. (2020), employees perform well when they are provided with external financial rewards. Therefore, a high level of involvement within an organisational culture does not necessarily prove to be a positive influence on organisational performance.

There is also a need to focus on certain other key elements, such as financial rewards and person-organisation fit, in order to achieve improved organisational performance. In addition to this, the current study does not support the hypothesis that consistency has a significant impact on organisational performance. This is in contrast with the findings of Minbaeva (2016), who claimsthat consistency within an organisation is extremely important for enhancing its performance. Furthermore, Lee et al. (2019) claims that when there is a need to significantly improve the performance of an organisation, there is also a need to ensure a high level of consistency within the firm. The integration between key business activities and a firm's objectives is extremely important for ensuring long-term success. However, the findings of the current study are supported by those of Dirisu et al. (2018), who argue that consistency does not always result in enhancing the performance of an organisation. There is a possibility that while consistency is present within an organisation, employees may not be that committed to their work, and as a result, they do not have an input in enhancing the performance of the firm. Hence, it is not always important to have improved organisational performance, while having a high level of consistency within the culture.

Moreover, the present study has revealed that intrapreneurship significantly mediates the relationship between adaptability and organisational performance. A high level of adaptability within the organisational culture helps the employees of a firm to show some creativity and innovation, because they show a high level of flexibility. This means that it is easier for them to adapt to certain changes. This is consistent with the findings of Carvalho et al. (2019), who argue that a high level of adaptability is important, in order to achieve entrepreneurship, because intrapreneurship is something which depends on firm's ability to be flexible and get adjusted to certain types of changes and this ultimately makes the firm successful and having improved performance. Besides this, the study also supports the hypothesis that intrapreneurship significantly mediates the relationship between mission and organisational performance. As a result of having identified an appropriate mission of the firm, the firm can succeed in achieving intrapreneurship, which ultimately proves to be helpful in enhancing performance (Sozuer et al., 2017).

\section{CONCLUSION}

Based on the analysis conducted in this research study, organisational culture has a significant impact on organisational performance. However, not all four of the elements significantly affect organisational performance. The two most important elements of organisational culture are adaptability and mission, which significantly affect the organisational performance. In addition to this, intrapreneurship significantly mediates the relationship between adaptability, mission, and organisational performance. The managers of organisations are required to give careful consideration to adaptability and mission as important elements of organisational culture, in order to ensure strong intrapreneurship and to ultimately enhance organisational performance. A firm's organisational culture has a significant impact on the attitude and performance of its employees. For employees, organisational culture is considered as either a glue by which people are bonded to an organisation, or as a means to driving them away. It includes a set of norms and standards by which employees' behaviour is prescribed in a workplace.

\section{Theoretical contribution}

This study adds value to the literature, in terms of studying both the direct and indirect effect of organisational culture on organisational performance. While previous studies have investigated the importance of organisational culture for the success of organisations, this study adds value to the literature by focusing specifically on Denison's model of organisational culture. The key focus is on four key elements of organisational culture, along with studying the mediating effect of intrapreneurship on the relationship between four elements of organisational culture and performance. While some previous studies investigated the importance of organisational culture, very few focused on examining the four important elements of organisational culture, as identified through Denison's model. In 
this way, the current study adds value to the literature and makes a theoretical contribution. Moreover, none of the existing research studies focused on examining the mediating effect of intrapreneurship on the relationship between key elements of organisational culture and performance. Intrapreneurship is one of the most important elements linked to long-term success and the competitiveness of organisations. It has become extremely important for organisations to focus on intrapreneurship, in order to gain a competitive edge. However, none of the existing studies examined its relationship with organisational culture and performance. So, this research study adds value to the literature in terms of investigating the mediating effect of intrapreneurship on the relationship between organisational culture and performance.

\section{Practical implications}

The findings of this research study will be useful for hotel managers, in terms of getting key insights about the importance of four important elements of organisational culture for enhancing organisational performance. They can learn which elements of organisational culture need careful consideration, in order to ensure improved performance. Moreover, employees working in the hospitality industry can get an understanding of the key aspects of organisational culture, which need to be considered carefully, in order to enhance overall performance. They can also get an understanding of the role played by intrapreneurship in enhancing organisational performance, while becoming influenced through organisational culture. As it is not possible for organisations to succeed in the market without focusing on entrepreneurship, this study provides key insights into the significance of intrapreneurship in terms of enhancing the performance of an organisation. This research study has certain implications for managers in the hospitality industry, and which they can apply, in order to enhance overall performance. This study recommends that mission is the most significant cultural trait that must be considered in contemporary organisations within the hospitality industry. It is important for managers and employees to have the appropriate knowledge of the key mission and the purpose of the business (Chilla et al., 2014). Mission is one of the most important units of culture, which can help to bring about an improvement in the overall performance of an organisation (Bohle et al., 2017). Besides this, adaptability is known as an important predictor of organisational performance. The culture of an organisation plays a key role in improving performance of organisation, especially when it adapts to changing business environment. In addition to this, it is found that intrapreneurship is one of the most important elements, which can help in enhancing profitability of the firm. One practical implication is that hotels' managers must not only support the development of held values among the members of organisation, but they are also required to focus on how culture is geared towards external contingencies (Dlamini et al., 2017). When managers in an organisation consider consistency as an important element of organisational culture, they can also focus on adopting an employee-focused leadership approach. Managers in an organisational culture with a high level of adaptability can focus on building good relationships with employees. They consider their employees as highly valuable and allow them to adapt to all kinds of changing circumstances. In a highly adaptable organisational culture, leaders build good relationship with employees, in order to make them aware of key changes. This ultimately results in enhancing satisfaction and motivation level among employees, and in achieving innovation. Moreover, employees also start to show loyalty for the firm, as well as a high level of commitment towards their work. As a result, the performance of the whole organisation is enhanced (Presbitero and Attar, 2018).

\section{Limitations and directions for future research}

While this research study has various theoretical and practical implications, there are also some limitations. First of all, it examined onlyl four key elements of organisational culture. However, future research studies could focus on investigating other important elements, such as effective communication, leadership, community, and purpose. Moreover, the sample size selected in this research study is much smaller, which could be increased in future research studies. In addition to this, the future research study could focus on investigating other mediating variable, such as entrepreneurial leadership. 


\section{References}

Ahammad, M. F., Tarba, S. Y., Liu, Y. and Glaister, K. W. (2016). Knowledge transfer and cross-border acquisition performance: The impact of cultural distance and employee retention. International Business Review, 25(1), 66-75. Doi: https://doi. org/10.1016/j.ibusrev.2014.06.015

Albright, J.J. and Park, H.M. (2009). Confirmatory factor analysis using Amos, LISREL, Mplus, and SAS/STAT CALIS, working paper, The University Information Technology Services (UITS) Center for Statistical and Mathematical Computing, Indiana University, available at: www.indiana. edu/ statmath/stat/all/cfa/index.html

Ana-Maria, G., Florica, B. and Cătălina, R. (2010). Modern instruments for measuring organizational performance. Annals of the University of Oradea, Economic Science Series, 19(2), 951-956. Doi: doi. org/0912f50748d403a334000000

Arjona-Fuentes, J. M., Ariza-Montes, A., Han, H. and Law, R. (2019). Silent threat of presenteeism in the hospitality industry: examining individual, organisational and physical/mental health factors. International Journal of Hospitality Management, 82, 191-198. https://doi. org/10.1016/j.ijhm.2019.05.005

Baron, R. M. and Kenny, D. A. (1986). The moderatormediator variable distinction in social psychological research: Conceptual, strategic, and statistical considerations. Journal of Personality and Social Psychology, 51(6), 1173. Doi: 0022-3514/86/ S00.75

Bendak, S., Shikhli, A. M. and Abdel-Razek, R. H. (2020). How changing organizational culture can enhance innovation: Development of the innovative culture enhancement framework. Cogent Business \& Management, 7(1), 1712125. Doi: https://psycnet. apa.org/buy/1987-13085-001

Bohle, P., Knox, A., Noone, J., Mc Namara, M., Rafalski, J. and Quinlan, M. (2017). Work organisation, bullying and intention to leave in the hospitality industry. Employee Relations. 39 (4), 446-458. https://doi.org/10.1108/ER-07-2016-0149

Carraher, S. M., Welsh, D. H. and Svilokos, A. (2016). Validation of a measure of social entrepreneurship. European Journal of International Management, 10(4), 386-402. Doi: https://doi. org/10.1504/EJIM.2016.077421

Carvalho, A. M., Sampaio, P., Rebentisch, E., Carvalho, J. Á. and Saraiva, P. (2019). Operational excellence, organisational culture and agility: the missing link?. Total Quality Management \& Business Excellence, 30 (13-14), 1495-1514. Doi: https://doi. org/10.1080/14783363.2017.1374833

Chahal, H. S. and Poonam. (2017). Study of organizational culture, employee turnover and employees' retention in hospitality sector. Pacific Business Review International, 9(11), 119-125.

Chilla, H. A., Kibet, Y. and Douglas, M. (2014). Effects of Organizational Culture on Organizational Performance in the Hospitality Industry. International Journal of Business and Management Invention, 3(1), 1-13.

Chen, J., Jiao, L. and Harrison, G. (2019). Organisational culture and enterprise risk management: The Australian not $\square$ for $\square$ profitcontext. Australian Journal of Public Administration, 78(3), 432-448. Doi: https://doi.org/10.1111/1467-8500.12382

Cooke, R. A. and Rousseau, D. M. (1998). Behavioral norms and expectations: A quantitative approach to the assessment of organizational culture, structure, and performance. Research in Industry Development, 6, 295-327. Doi: https://doi. org/10.1177/105960118801300302

Cui, Y., Liu, Y. and Mou, J. (2018). Bibliometric analysis of organisational culture using CiteSpace. South African Journal of Economic and Management Sciences, 21(1), 1-12.

Denison, D. R. (1990). Corporate Culture and Organizational Effectiveness, New York: John Wiley \& Sons.

Denison, D. R. and Mishra, A. K. (1995). 'Toward a Theory of Organizational Culture and Effectiveness', Organization Science, 6 (2), 204-223. https://doi. org/10.1287/orsc.6.2.204

Denison, D., Nieminen, L. and Kotrba, L. (2014). Diagnosing organizational cultures: A conceptual and empirical review of culture effectiveness surveys. European Journal of Work and Organizational Psychology, 23(1), 145-161. https:// doi.org/10.1080/1359432X.2012.713173

Dirisu, J., Worlu, R., Osibanjo, A., Salau, O., Borishade, T., Meninwa, S. and Atolagbe, T. (2018). An integrated dataset on organisational culture, job satisfaction and performance in the hospitality industry. Data in Brief, 19, 317-321. Doi: https://doi. org/10.1016/j.dib.2018.04.137

Dlamini, N. N. N., Garg, A. K. and Muchie, M. (2017). The impact of transformational leadership style on organisational commitment in the hospitality 
industry. African Journal of Hospitality, Tourism and Leisure, 6(3), 1-21.

Erthal, A. and Marques, L. (2018). National culture and organisational culture in lean organisations: a systematic review. Production Planning \& Control, 29(8), 668-687. https://doi.org/10.1080/09 537287.2018 .1455233

Gürkan, G. Ç. and Çiftci, G. (2020). Developing a supportive culture in digital transformation. In Digital Business Strategies in Blockchain Ecosystems (pp. 83-102). Springer, Cham.

Halim, H. A., Ahmad, N. H. and Ramayah, T. (2019). Sustaining the Innovation Culture in SMEs: The Importance of Organisational Culture, Organisational Learning and Market Orientation. Asian Journal of Business Research, 9(2), 14. Doi: 10.14707/ajbr.190059

Heinonen, J. and Korvela, K. (2003, September). How about measuring intrapreneurship. In 33rd EISB Conference, Milan, Italy.

Hofstede, G. H., Hofstede, G. J. and Minkov, M. (2005). Cultures and organizations: Software of the Mind (Vol. 2). New York: Mcgraw-hill.

Ibarra-Cisneros, M.A., Hernández-Perlines, F. and Rodríguez-García, M. (2020) 'Intellectual capital, organisational performance and competitive advantage', European J. International Management, Vol. 14, No. 6, pp.976-998.

Kaouache, R., Brewer, G. A. and Kaouache, D. E. (2020). Existing and preferred organizational culture in public organizations: The case of an electricity power plant in Algeria. Journal of Transnational Management, 25(2), 154-171. Doi: http://doi.org/10.9770/jesi.2020.8.1(13)

Kyriacou, E. and Panigyrakis, G.G. (2020). Organisational culture at higher educational institutions: The importance of internal marketing. Journal of Cultural Marketing Strategy 4(2), 161171.

Lee, Y., Howe, M. and Kreiser, P. M. (2019). Organisational culture and entrepreneurial orientation: An orthogonal perspective of individualism and collectivism. International Small Business Journal, 37(2), 125-152. Doi: https://doi. org/10.1177/0266242618809507

Lockhart, P., Shahani, N. K. and Bhanugopan, R. (2020). Do organisational culture and national culture mediate the relationship between high-performance human resource management practices and organizational citizenship behaviour? International Journal of Manpower, 1(2), 78-98. Doi: https://doi. org/10.1108/IJM-04-2018-0129
Low, W. W., Abdul-Rahman, H. and Zakaria, N. (2020). Organisational culture of Malaysian international construction organisations. International Journal of Construction Management, 20(2), 105-121. Doi: https://doi.org/10.1080/15623599.2018.148455

MacKenzie, S. B. and Podsakoff, P. M. (2012). Common method bias in marketing: Causes, mechanisms, and procedural remedies. Journal of Retailing, 88(4), 542-555. Doi: https://doi. org/10.1016/j.jretai.2012.08.001

Mair, P., Borg, I. and Rusch, T. (2016). Goodness-offit assessment in multidimensional scaling and unfolding. Multivariate Behavioral Research, 51(6), 772-789. Doi: doi/abs/10.1080/00273171.2016.12 35966

Manning, L. (2018). The value of food safety culture to the hospitality industry. Worldwide Hospitality and Tourism Themes, 10(3), 284-296. https://doi. org/10.1108/WHATT-02-2018-0008

Mason, C. M., Box, P. J. and Burns, S. M. (2020). Research data sharing in the Australian national science agency: Understanding the relative importance of organisational, disciplinary and domain-specific influences. Plos One, 15(8), e0238071. Doi: https://doi.org/10.1371/journal. pone.0238071

Mees, B., McMurray, A. and Chhetri, P. (2016). Organisational resilience and emergency management. Australian Journal of Emergency Management, The, 31 (2), 38. Doi:33103181159877

Miller, D. W., Ngunjiri, F. W. and LoRusso, J. D. (2017). Human resources perceptions of corporate chaplains: enhancing positive organizational culture. Journal of Management, Spirituality \& Religion, 14(3), 196-215. https://doi.org/10.1080/1 4766086.2016.1260044

Minbaeva, D. (2016). Contextualising the individual in international management research: Black boxes, comfort zones and a future research agenda. European Journal of International Management, 10(1), 95-104. Doi: https://doi. org/10.1504/EJIM.2016.073990

Odor, H. O. (2018). Organisational culture and dynamics. Global Journal of Management and Business Research, 18(1), 23-29.

Ooi, S. K., Ooi, C. A. and Memon, K. R. (2020). The role of CSR oriented organisational culture in eco-innovation practices. World Review of Entrepreneurship, Management and Sustainable Development, 16(5), 538-556. Doi: https://doi. org/10.1504/WREMSD.2020.110451

Podsakoff, P. M., MacKenzie, S. B., Lee, J. Y. and Podsakoff, N. P. (2003). Common method biases 
in behavioral research: a critical review of the literature and recommended remedies. Journal of Applied Psychology, 88(5), 879. Doi: 10.1037/00219010.88.5.879

Podsakoff, N. P., Whiting, S. W., Welsh, D. T. and Mai, K. M. (2013). Surveying for "artifacts": The susceptibility of the OCB-performance evaluation relationship to common rater, item, and measurement context effects. Journal of Applied Psychology, 98(5), 863-874. https://doi. org/10.1037/a0032588

Presbitero, A. and Attar, H. (2018). Intercultural communication effectiveness, cultural intelligence and knowledge sharing: Ehxtending anxietyuncertainty management theory. International Journal of Intercultural Relations, 67, 35-43. Doi: https://doi.org/10.1016/j.ijintrel.2018.08.004

Quelhas, A. D., Filho, J. R. F., Neto, J. V. and Pereira, V. (2019). Model to measure adherence of culture, climate, and organizational behavior in a construction company. Journal of Management in Engineering, 35 (4). https://doi.org/10.1061/ (ASCE)ME.1943-5479.0000688

Rahimi, R. (2017). Customer relationship management (people, process and technology) and organisational culture in hotels. International Journal of Contemporary Hospitality Management. 29 (5), 1380-1402. https://doi.org/10.1108/ IJCHM-10-2015-0617

Reino, A., Rõigas, K. and Müürsepp, M. (2020). Connections between organisational culture and financial performance in Estonian service and production companies. Baltic Journal of Management. 15 (3), 375-393. Doi. https://doi. org/10.1108/BJM-01-2019-0017

Richter, N. F., Hauff, S., Schlaegel, C., Gudergan, S., Ringle, C. M. and Gunkel, M. (2016). Using cultural archetypes in cross-cultural management studies. Journal of International Management, 22(1), 63-83. Doi: https://doi. org/10.1016/j.intman.2015.09.001

Romani, L., Barmeyer, C., Primecz, H. and Pilhofer, K. (2018). Cross-cultural management studies: state of the field in the four research paradigms. International Studies of Management \& Organization, 48(3), 247-263. Doi: https://doi.org/1 $0.1080 / 00208825.2018 .1480918$

Roscoe, S., Subramanian, N., Jabbour, C. J. and Chong, T. (2019). Green human resource management and the enablers of green organisational culture: Enhancing a firm's environmental performance for sustainable development. Business Strategy and the Environment, 28(5), 737-749. https://doi. org/10.1002/bse.2277

Sahibzada, U. F., Jianfeng, C., Latif, K. F., Shah, S. A. and Sahibzada, H. F. (2020). Refuelling knowledge management processes towards organisational performance: mediating role of creative organisational learning. Knowledge Management Research \& Practice, 1-13. https://doi.org/10.1080/ 14778238.2020.1787802

Scuotto, V., Giudice, M. D., Holden, N. and Mattiacci, A. (2017). Entrepreneurial settings within global family firms: research perspectives from cross-cultural knowledge management studies. European Journal of International Management, 11(4), 469-489. Doi: https://doi.org/10.1504/EJIM.2017.085586

Sebastião, S. P., Zulato, G. and Trindade, A. D. (2017). Internal communication and organisational culture: The management interplay in the view of the Portuguese communication consultant. Public Relations Review, 43(4), 863-871. Doi: https://doi. org/10.1016/j.pubrev.2017.05.006

Segovia-Pérez, M., Figueroa-Domecq, C., Fuentes-Moraleda, L. and Muñoz-Mazón, A. (2019). Incorporating a gender approach in the hospitality industry: Female executives' perceptions. International Journal of Hospitality Management, 76, 184-193. https://doi. org/10.1016/j.jijhm.2018.05.008

Shahriari, M. and Allameh, S. M. (2020). Organizational culture and organizational learning: does high performance work systems mediate?. 32 (8), 583597. Journal of Workplace Learning. https://doi. org/10.1108/JWL-03-2020-0047

Sinha, N. and Dhall, N. (2020) Mediating effect of TQM on relationship between organisational culture and performance: evidence from Indian SMEs, Total Quality Management \& Business Excellence, 31:15-16, 1841-1865, DOI: 10.1080/14783363.2018.1511372

Sozuer, A., Altuntas, G. and Semercioz, F. (2017). International entrepreneurship of small firms and their export market performance. European Journal of International Management, 11(3), 365-382. Doi: https://doi.org/10.1504/EJIM.2017.083874

Tortorella, G. L., Fettermann, D., Fogliatto, F. S., Kumar, M. and Jurburg, D. (2020). Analysing the influence of organisational culture and leadership styles on the implementation of lean manufacturing. Production Planning \& Control, 1-13. Doi: https://doi.org/10.10 80/09537287.2020.1799255

Úbeda-García, M., Claver-Cortés, E., Marco-Lajara, B., Zaragoza-Sáez, P. and García-Lillo, F. (2018). High performance work system and 
performance: Opening the black box through the organizational ambidexterity and human resource flexibility. Journal of Business Research, 88, 397-406. Doi: https://doi.org/10.1016/j. jbusres.2017.12.045

Van Rhee, H. and Dul, J. (2018). Filling the black-box of HR: Unraveling the AMO model and elevating it to the organizational level. In Academy of Management Proceedings (Vol. 2018, No. 1, p. 13840). Briarcliff Manor, NY 10510: Academy of Management.

Vnoučková, L. and Urbancová, H. (2020). Setting Organisational Culture to Develop Potential and Innovativeness. Quality Innovation
Prosperity, 24(1), 54-68. Doi: http://dx.doi. org/10.12776/qip.v24i1.1346

Wziątek-Staśko, A., Stańczyk, I. and Stuss, M. M. (2020). Organisational culture as a stress determinant in SME sector organisations. European Journal of International Management, 14(6), 955-975. Doi: https://doi.org/10.1504/EJIM.2020.110586

Zucchella, A., Strange, R. N. and Mascherpa, S. (2019). Which organisational capabilities matter for SME export performance?. European Journal of International Management, 13(4), 454-478. Doi: https://doi.org/10.1504/EJIM.2019.100812 